\title{
Multi-Touch Collaborative Gesture Recognition Based User Interfaces as Behavioral Interventions for Children with Autistic Spectrum Disorder: A Review
}

\author{
AHMED HASSAN*, MUHAMMAD SHAFI*, AND MUHAMMAD IRFAN KHATTAK** \\ RECEIVED ON 01.07.2015 ACCEPTED ON 16.09.2015
}

\begin{abstract}
This paper addresses UI (User Interface) designing based on multi-touch collaborative gesture recognition meant for ASD (Autism Spectrum Disorder) - affected children. The present user interfaces (in the context of behavioral interventions for Autism Spectrum disorder) are investigated in detail. Thorough comparison has been made among various groups of these UIs. Advantages and limitations of these interfaces are discussed and future directions for the design of such interfaces are suggested.
\end{abstract}

Key Words: Autism Spectrum Disorders, Child Computer Interaction, Multi-Touch User Interfaces, Behavioral Interventions.

\section{INTRODUCTION}

$\mathrm{N}$ euro developmental disorders are growth impairments of the brain that directly affect the memory, emotions, self-control and socializing skills of an individual. At present Autism is one of the most widely spreading disorders throughout the world, which affects the social and communication skills of the affected person [1]. The symptoms of Autism start to appear before the child is three years old [1]. The disorder is hence diagnosed and cured in the early childhood. If not done so, the child takes the impairments along to his adulthood. This hinders his practical life up to the point that the disorder takes severe shapes. A survey done in the year 2010 tells that the ratio of children with ASD has risen to 1 in 88 in the US [2]; while an incidence rate of 1,755 ASD cases was extrapolated for the population of Pakistan [3].
Autism spectrum further classifies into three acclaimed disorders, namely: ASD, Asperger Syndrome and PDDNOS (Pervasive Development Disorder-Not Otherwise Specified). Moreover, another classification has also been adapted mostly by the concerned therapists and researchers: HF (High-Functioning) ASD, LF (Low Functioning) ASD and TD (Typically Developing). Along with other medicinal and therapeutic treatments, research in technology with special concern to the treatment of ASD is underway. Major diversities of the related research are in the areas of CCI (Child Computer Interaction), HCI (Human Computer Interaction), tangible interaction games, video modeling and home activity recording devices [4]. The center of attention of the current research is $\mathrm{CCI}$ in general and multi-touch UIs with collaborative gesture recognition, in particular.

\section{* Department of Computer Software Engineering, University of Engineering \& Technology, Mardan.}

** Department of Electrical Engineering, University of Engineering \& Technology, Peshawar.

Mehran University Research Journal of Engineering \& Technology, Volume 35, No. 4, October, 2016 [p-ISSN: 0254-7821, e-ISSN: 2413-7219] 
Multi touch screens are an innovation to the world of technologies for Autistic support. Contrary to the traditional interfaces, a user can utilize the graphical interface with a natural way of interaction with multi touch screens. They also support multi-user interaction. Therefore, multi-touch-enabled UIs prove exceptionally benefitting in the enhancement of social skills among Autistic children.

This paper focuses on exploration of the aptitude of multitouch UIs with collaborative gesture recognition to engage children with ASD in social activities. This is intended to achieve an approximate figure of how applications with these UIs are able to enable the ASD affected children to work in partnership, be social, express their feelings and opinions and to approach a normal life till they get to their adulthood.

The rest of this paper is organized as follows: Section 2 describes the methodology followed to conduct this analytic study, 2.1 briefs about the necessary notion of requirements and expectations of the targeted users; i.e. the children. This section also explains the type of interfaces being designed under the umbrella of CCI. Furthermore, Section 2.2-2.7 discuss the on hand literature on UI development, with special reference to ASD specific applications and related UIs. Findings of the analysis are summarized in Section 3; while, Section 4 concludes the scrutiny by giving the results and deductions of the aforementioned study.

\section{MATERIALS AND METHOD}

The objective of this study is to gain an insight and understanding of the trends of UI designing in terms of multi-touch UIs with collaborative gesture recognition. It also aims to aid in social collaborative treatment of ASD affected children. To achieve this, a careful analysis of the available literature was done. The information gathering was initially aimed at reviews done in various dimensions in this regard. It later converged to individual UIs designed for different commercial projects and multitouch applications to support the treatment of children with Autistic conditions. The UI design strategies that have been surveyed and the reviewing methodologies are summarized in Fig. 1. Relevant data were finally collected from selected papers. Section 3 of this paper summarizes this data.

\subsection{ASD Specific Requirements of A CCI User Interface}

CI has been a distinctive area in HCI research since 2002 when the need of a structured community for Child Interface Design was first spotted [5]. CCI has now gained the status of such a broad field in itself that it has recently been recognized as an IFIP (International Federation for Information Processing) work group [5].

There are numerous situations of children's interaction with computers where they need enhanced interfaces.

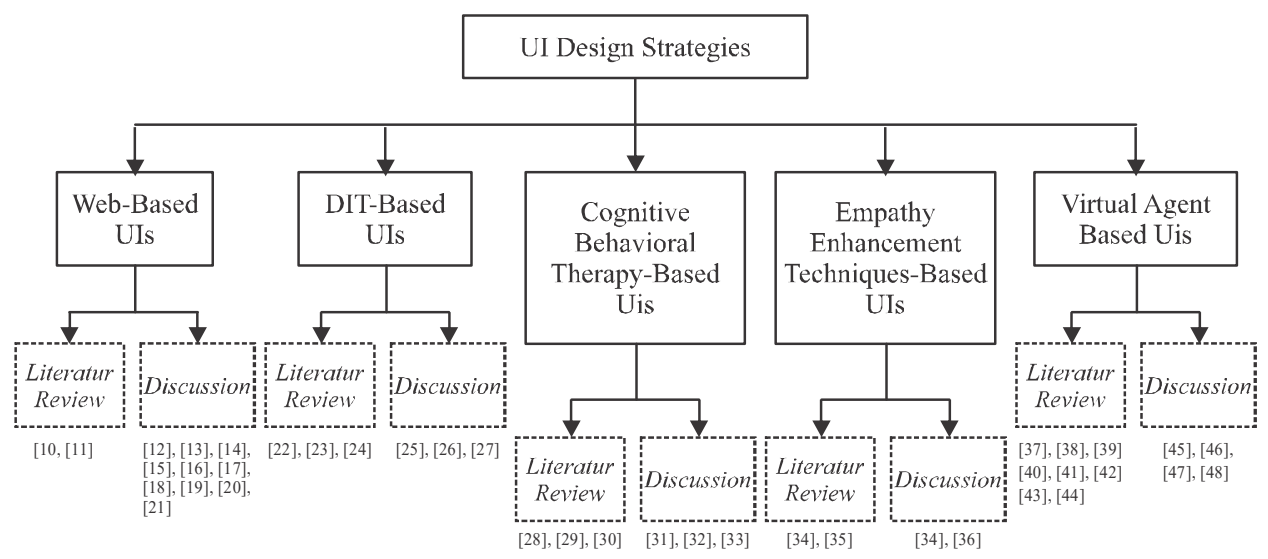

FIG. 1. REVIEW METHODOLOGY 
Attempts have already been made by researchers in this field to divert the attention of HCI experts towards easy use of search engines and digital libraries by children [6]. The main idea behind this work was the use of a graphical interface design for a system with information visualization. The survey done in [6] shows that the use of a graphical interface design for search operations gives faster searches and efficient gain of knowledge by the respondent children, when compared to the use of textbased search interfaces.

Before analyzing the developments in CCI and to anticipate the goals that are yet to be achieved, there is a need to look into the requirements of the targeted users. This would help in foreseeing as to what kind of user interfaces for child usage are going to be popular in the next generation of interface designing. In the present case of research, target community of users is children in general and children disabled with ASD in particular. Researchers have made numerous attempts for different purposes to identify the needs of various groups of children. This has been done by means of surveys, interviews and interactive questionnaire-based games. One such piece of work has been composed in [7], which has focused on the responses from a group of deaf children using a computer game application. The conclusions made by the authors of [7] point out that children are adjustable with interfaces they are not so familiar with. They also point out that in the contrary they expect intuition and more innovation in the technology that lets their creativity be refined. This challenge is note-worthy when seen in the perspective of special children like disabled due to physical or mental diseases, specifically Autism.

Why do children with ASD find using software and gadget based activities more interesting than socializing with friends and peers? The answer to this question has been found in literature when researchers first started on the voyage to solve the ASD challenges with technology. One answer has been found in [8]. According to this, the reason behind ASD affected children's inclination towards technological learning is that they get freedom and solitude in such activities; they do not have to interact much with other people. It is therefore a plus point in their treatment. Research has already proved that involving technology is helpful to a great extent in the development of children affected with ASD.

\subsection{Multi-Touch UIs for Behavioural Interventions in the Treatment of ASD: Review and Discussion}

An influential attempt on the development of an interface helping Autism patients to interact more with their peers has been found in [9]. The need arose since children affected by Autism are less fond of socializing with peers, as compared to the normal children. This interface has been designed for the sake of improving such children's social life and their interaction with class mates and friends [9]. The main objective of the concerned UI designers has always been to let the child engage in a certain socializing activity without letting him get aware with the purpose of it. This is mandatory as children with the Autism tend to become aggressive when they are forced to respond and get social with their peers. In order to make this, the interface designing needs to be highly specialized and HCI enabled to let the child be grasped in the activity without aggravating him. The study conducted in [9] is a comparative analysis of an interface built specially for the enhancement of socializing in the Autism-affected and one standard interface. The results revealed that children with Autism responded more when they used the specially built interface. One important point gained from this study is that the kind of interface design under current study needs an activity designed specifically to support the interface. For this, the interface designer needs to have strong background knowledge of the psyche of such children. Moreover, he needs to integrate the findings of HCI into his design, without which efficient interface design would not be successful.

Mehran University Research Journal of Engineering \& Technology, Volume 35, No. 4, October, 2016 [p-ISSN: 0254-7821, e-ISSN: 2413-7219] 
Autism treatment naturally falls into two categories; namely, medical treatment and educational interventions. Focusing on user interfaces for Autism treatment, the current work falls into the second category. As the medical treatment follows medication, dietary plans and neurological therapies, educational interventions have a wide and diverse classification. A generalized categorization of Autism interventions and therapies - in the context of educational treatment - has been elaborated in Fig. 2.

Reviews and analytic surveys present in the literature have been done from two aspects. One is the pure ASD school-of-thought and the other is a user interface design school-of-thought. What lacks in this regard is a crosslayer review methodology that covers the available UIs from an ASD specialist's view point.

When working in this domain, it is essential to mention that this amalgamation in itself is a diverse subject matter to be reviewed. Converging the discussion to one of the several categories of UI designing and one of the several types of Autism therapies, the current review is focused on the following aspects of both dimensions:
- UI design type: Multi-touch UIs

- Autism treatment type: Behavioral interventions

Furthermore, it is noteworthy here that behavioral therapies have a wide classification. Out of these, only those interventions have been included in the review, that are the most commonly aimed in software apps.

\subsection{User Interfaces Supporting Autism Advocacy Over the Web}

The inspiration to use collaborative gesture recognition based interfaces for Autism Spectrum and the related disorders' treatment has emerged from the success of such interfaces in console and desktop games. The ASC inclusion project referred in [10] is an integration of the recognition and record of various socializing activities of ASD affected children. Main job of the involved interfaces is to recognize user's facial, gesture and vocal expressions. The interface used in this collaborative project was based on a gaming platform that made progressive development by starting from the three modules of face, voice and gesture analyzers. It later advanced to interactive training

Types of Educational Interventions \& Therapies for Autism

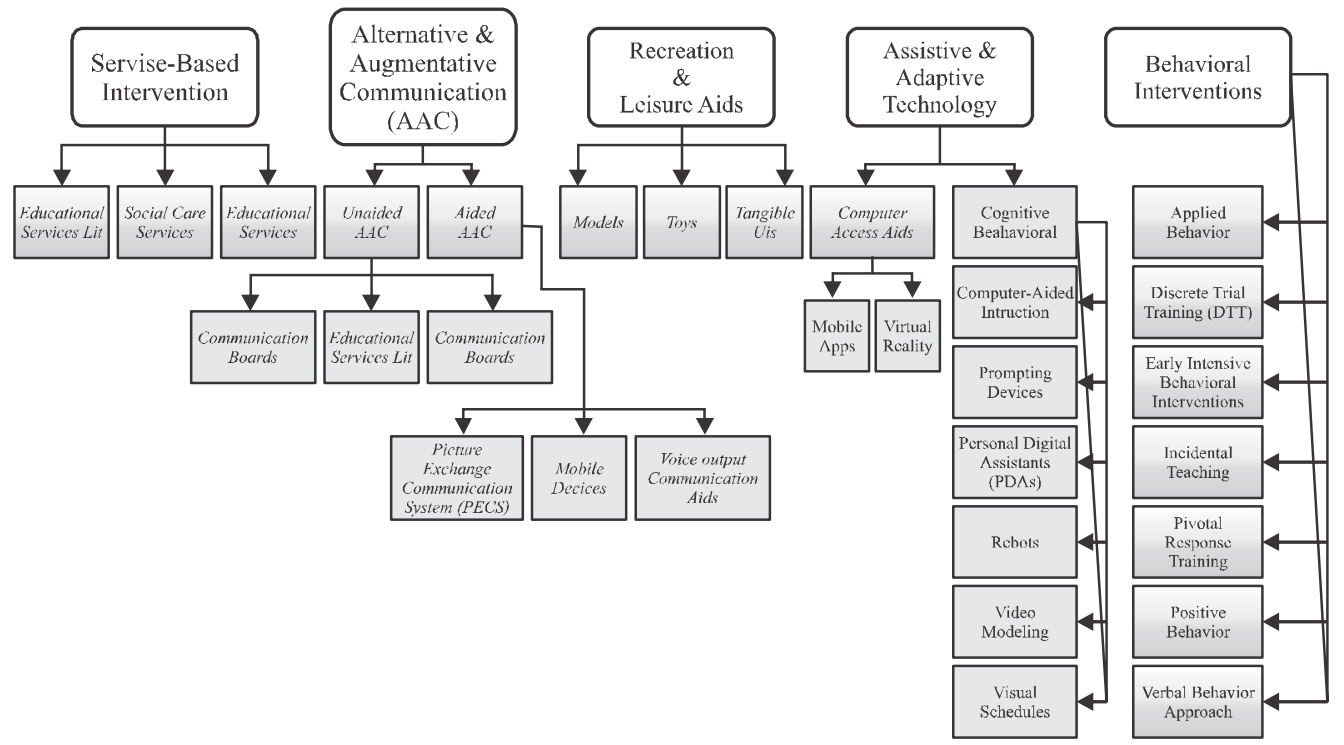

FIG. 2. CLASSIFICATION OF EDUCATIONAL INTERVENTIONS IN THE TREATMENT OF ASD 
lessons and more intelligent gaming interface development for the ASD affected children. The authors of [10] have also done a survey on their project and found a satisfactory rating by the respondents. Another such survey has been found in [11] in which the main objective was to investigate the usefulness of a web-based portal i.e. the IAN (Interactive Autism Network). At one place, this online registry has made the diagnosis and treatment of ASD affected children easier for the parents; at the other place, it has bridged the gap between researchers and families related to ASD. One of such online polls has been shown in Fig. 3.

Virtual communities and online discussion forums such as Wrong Planet [12] help an Autistic individual socialize on his own. The most constructive feature in such UIs is that the Autistic individual feels free to communicate with the world, without any social anxiety and with much engrossed empathy. Another such forum named as Together for Autism (developed in 2009) has an objective similar to [12] with around 14,000 posts and 24,000 members including Autistics and their parents. Here, they discuss the difficulties they face and get awareness about concerned health issues and other socializing problems. One other attempt was narrated in [13], describing a blog created by a bunch of high functioning Autistics. The

\section{WEBSITE POLL}

How much exercise does your child with autism get?

O More than most people his or her age.

O As much as most people his/her age.

O Not as much as most people his/gher age.

O Very little.

\section{Vote}

- Older Polls

- Results

FIG. 3. ONLINE POLL OBTAINED FROM WEB INTERFACE OF IAN (IMAGE ADAPTED FROM THE WEBSITE OF IAN) study shows the good that the web can do in development of such individuals. These people discuss their uniqueness in their blogs, highlighting the optimism of their minds in spite of the mental incompetence that they suffer. Other such blogs and online communities have been discussed in $[14,15]$. One of these blogs is named as "We go with him" where the mother of a 10-year old Autistic describes her happy experiences when her child progresses and tries to gain 'joint attention' with elders and grandparents. One such review has also been found in [16], where the authors have discussed the pros of Autism Advocacy for Autistic children and their parents. Moreover, researchers like the authors of [17] have developed user interfaces having online surveys for parents of the Autistics. These surveys provide convenience to the parents and help them gain detailed feedback about the related issues.

Among the negative consequences that come sidewise with the benefits of web-based UIs is the fact that inappropriate information travels over the web as easily as does the useful information. Scams and advertisements of expensive Autism treatments also travel through the UIs using web. This misleads the parents of Autistic children [18]. Yet another issue that has risen due to the UIs that involve web is that of splintering within the Autism society. One such matter has been addressed in [19] explaining that the increased discussion about Autism and its causes by the Autism activists has led some to conclude that Vaccines are the ultimate cause of this mental disorder. Science does not support this inference. Furthermore, such information and its use in UIs lead to incorrect and risky self-diagnosis by the Autistic and Asperger-Syndrome-affected individuals. This selfdiagnosis may lead people with personality disorders to conclude with having Asperger Syndrome [20].

\subsection{Discrete Trial Training-Based UIs}

DTT (Discrete Trial Training) is an interactive pedagogical approach used to teach skills in a planned, controlled, 
and orderly manner. DTT finds its use in cases where there is a need to teach a specific skill in small repeated steps. Each trial has a definite beginning and end, which justifies the name 'Discrete' trial training. Data collection, particularly involving the Autistic child's parents/teachers is an important feature of DTT sessions. User interfaces exist that serve this purpose. Due to the periodically intensive nature of DTT, it is effective to be used with younger children with age groups of 2-9 years.

Literature shows that interface designers have made numerous attempts to bring in designs with innovations that would aid the therapists and psychologists in the treatment of ASD patients. A group of researchers from the University of Dundee, Scotland in collaboration with the European Commission's COSPATIAL project designed an effective interface for ASD patients. The pilot study of this work has been described in [21]. In this user-centered approach of work, they have presented the prototype of an audio-augmented paper that can be used to record and play the child's discussion with his therapist. This is shown in Fig. 4. The sheet-of-paper based interface consists of two tags of record and play. These tags when hidden under the user's hand while drawing on the paper - let the computer record and play the user's voice.
This activity helps therapist in keeping the user engaged without his awareness of being treated. Meanwhile, play back of the child's own voice helps to auto-treat the ASD disorder. Results gained from the prototype testing showed that such an interface is beneficial to help the child cope with his hesitation. At the same time, it helps the therapist to control the child's attention, cooperation and to get improved results in the treatment.

According to the review done on multi-touch table top based interfaces in [22], these interfaces require large sized touch displays that can be placed horizontally or can be mounted on a table top or desktop. The main purpose for the bigger size is to provide support for multi user cooperative gestures that have emerged as a recent modality to interact with computing devices according to the principles of HCI. The greatest advantage of such an interface is that it is post WIMP (Window, Icon, Menu and Pointer) [22].

The interface developed in [22] works in a fashion similar to [21] that is to record useful information and analyze the ASD subject's behavior while delivering the training. The proposed prototype, thus aims to help the trainer cum therapist to foster the child's attention on the trial

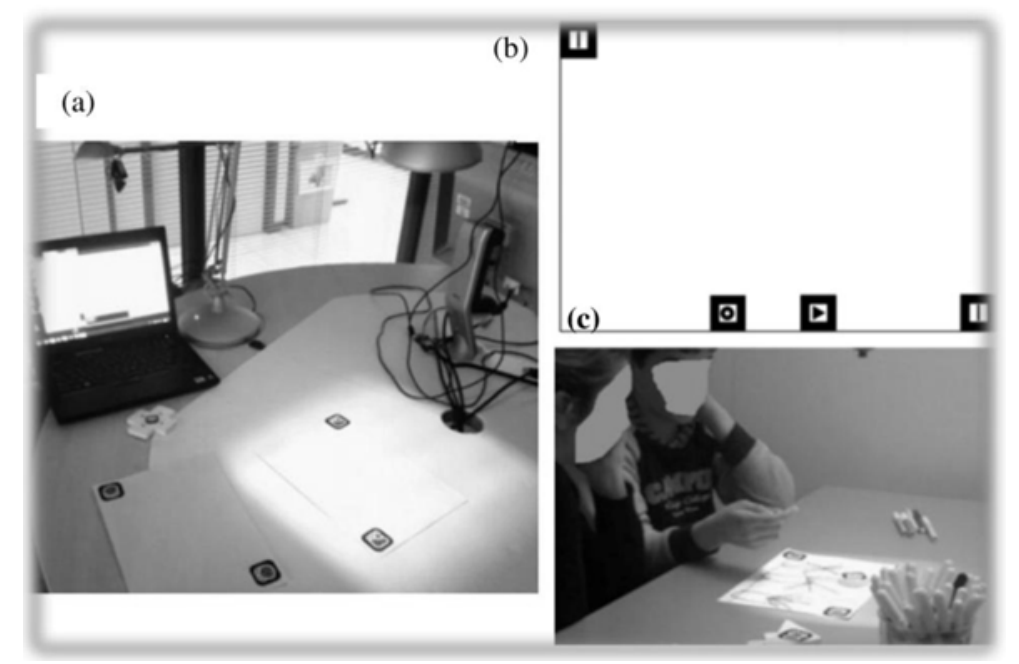

FIG. 4. AUDIO AUGMENTED PAPER APPLICATION IMPLYING DTT. (A)PROTOTYPE OF THE AUDIO AUGMENTED PAPER (B) MODEL OF THE PAPER WITH ITS MULTI-TOUCH FEATURES (C) SNAPSHOT FROM A DTT TRAINING SESSION (PHOTOS ADAPTED FROM [22])

Mehran University Research Journal of Engineering \& Technology, Volume 35, No. 4, October, 2016 [p-ISSN: 0254-7821, e-ISSN: 2413-7219] 
session. The train and track features in the designed application help the trainer select whether to conduct a trial or to go through the specific child's record of trainings. The main challenge in this regard is the need to conduct the trial and discussion with the child and to analyze the child's responses simultaneously. This makes the activity prone to errors, due to which research in CCI for Autistic children has found one of its routes oriented in this direction. According to the analysis done in [22], touch based UIs suit best to children with ASD and they find such applications more interesting than others. The table-top interface designed in [22] has followed the SCRUM software design method and Samsung SUR40 tabletop with Microsoft Pixel Sense has been used as the hardware. This configuration helps the ASD child to learn basic shapes and color recognition and he gets engaged without much usage of sensors.

Apart from proposing the prototype discussed above, authors of [22] have also identified the gap between already developed DTT apps and HCI expertise. As stated by the authors of [22], the DTT intervention based apps included in their review have mostly been designed by experts in behavior analysis. This has led to limitations in the designed user interfaces when viewed from an HCI expert's viewpoint. Therefore, there occurs to be a wide gap in terms of collaborative allowance, multiple touches $\&$ gestures allowance and interactive interface design. This is a significant point to be noticed by HCI experts in general and CCI experts in particular. Another important factor highlighted in this pilot study is that front end of the UIs developed for such children should be as simple as possible. This is so because ASD children are prone to over stimulations. They can get distracted from the training if the UI in front of them contains messy features that they don't understand or even if it contains variety of features.

On further investigation of tablet applications for Autistic children, we discovered that UIs with multi-touch collaborative gesture recognition have been worked on, not only for collaboration enhancement but also for the development of academic and language skills. Two applications have been developed at the National University of Singapore in this regard; namely, 'I Know' and 'I Can Tell' [23].

These applications were developed specifically for the IPad and are available on the app store. The main advantage of the UI is to the parents of the targeted children: parents can create quizzes of their choice and can edit the existing quizzes. Moreover, photos and audio from the child's daily life can also be added to the customized quiz.

As far as the other application 'I Can Tell' is concerned, it allows the ASD affected children to build stories from their daily lives. The UI of this application also enables parental control in a way that parents can add photos from the child's everyday life, based on which he can build a story using the side bars in the interface. Both the parent and the child can use the UI at the same time to develop the story. This provides enhanced communication and collaboration among the child and his parent [23].

With DTT, the Autistic child gets help in learning attention, imitation and working skills. The methodology followed in DTT helps the trainers in accurate data collection due to the systematically outlined procedure that they have to follow. This way, it becomes easier for them to record and monitor the child's progress [24]. DTT provides the ASD affected child with better learning habits, focusing more on his tolerance to demands which occur to him because of his aggressiveness. The ease that DTT provides for group learning makes it easier and habitual for the Autistic child to get mixed with peers in a group. This boosts his socializing and interacting skills.

The UI discussed in [12], is effective in terms of engaging the child in learning with a lesser use of sensors. A 
pronounced shortcoming of this attribute is noncollaborative allowance. This leads to the child's annoyance out of the lack of multiple features and space on screen. The authors of [25] have discussed the consequences of misapplication of DTT. According to them, the mistakes usually occur in the timing of trials, insufficient optimistic support by the trainers for the correct responses of the Autistic child and unnecessary pessimistic consequences for incorrect responses. To overcome this issue, [26] has presented a solution that specifies that the training sessions should be generalized so that multiple trainers could use the UI. It also states that there should be multiple environments to get a more realistic and better response on the average.

\subsection{INTEGRATION OF COGNITIVE- BEHAVIOURAL THERAPY AND UI DESIGNING}

The Story Table interface mentioned in [27] is yet another innovation done specifically for the HFASD affected children. This interface, as proposed by the authors is a cooperation-enforcing interface. It reflects their intercession based attempt to let the subjects interact with each other via the means of a story telling activity. The survey was based on a sample of 6 children aged 811 years.

The mention of the game suite in the field study done by the authors of [28] is an attempt made explicitly for HFASD affected children. The project under which this study has been done was essentially a multi-dimensional project that was based on a collaborative effort of CBT (CognitiveBehavioral Therapy) expert therapists and software interface designers. The authors also involved parents and teachers of HFASD affected children in this work. Their experimental group was based on 8 children, who after being tested came out to be more interactive and collaborative with their peers than before. A new term of 'ecological validity' in computer games was acknowledged in the work in [28]. This - if accounted for in interface designing - has been proved to be a progressive factor in the treatment of HFASD patients. A piece of work related to the same background in interface designing has been found in [29]. This work addresses a UI design model named as SCERTS, which is the acronym for SC (Social Communication), ER (Emotional Regulation) and TS (Transactional Support). This model has basically been derived from an empirical cognitive behavioral therapy based design methodology. The work done in [29] has also addressed the concept of 'ecological validity' with verification of the fact that this perception is helpful in effective user interface designing.

CBT based interfaces are built by developers, specifically to address aggressiveness and intellectual mutilation in Autistic children [30]. Literature shows that interfaces that are built for trainings based on CBT prove to be effective for the Autistic children with anxiety disorders [31]. As far as behavioral therapy based UIs for Autistic adults are considered, the survey performed in [32] shows that CBT has long term positive effects on adults with Autism. This influence includes reduction in symptoms of depression, distrust, sleeping problems, anxiety and agoraphobia.

Among the pitfalls in UIs centered on this technique, the most prominent one is the lack of visual aids, which has been proposed as a modification in CBT [32]. The authors of this case study have found room for implementing visual aids within behavioral treatment to provide better results and to achieve subject's interest to a comparatively higher level. Apart from this modification, the authors of [32] have also identified the need of physical activities within the therapies and involvement of the subject's parents to aid in his/ her treatment.

\subsection{UIs for Empathy Enhancement in ASD Patients}

The next relevant work reviewed is the development of a multi-touch UI based software for the ASD affected children of Chile, with the main focus to support enhancement of empathy in such children [33]. The 
mentioned software was developed using the UCD (User Centered Design) methodology. A note-worthy point in this approach is that the UI designers have considered, among other factors, Chilean culture as an important element in the design. This cultural feature in the designed application has reflected in the analyzed results given in [27]. According to these results, the designed application serves to be a good learning medium in context of cultural values for the ASD affected children. The Android application proposed in [33] can be downloaded via Google Play from [34].

The interface developed in [33] has been built specifically to develop the skill of empathy in the target children. According to the authors, when the child learns to understand the feelings and situation of other people, it makes him cooperative and more social. Furthermore, it also depreciates the aggressiveness and isolation in his nature. The designed application in [34] has been made with the intent of helping the trainer in particular to deliver the training session with ease, replacing paper based interventions with multi-touch interface.

The existing UIs made for emotion recognition, when applied to use for the development of empathy in Autistic individuals only fulfilled the job partially. The needs of an Autistic child in terms of empathy are described by Kaliouby, et. al. [34]. According to this comparative analysis, there is a room for improvement in such interfaces; which has been highlighted as the lack of 'Systematic' empathy. The requirement of an Autistic individual is far beyond just emotion recognition, for he needs a lot of training as to how to empathize someone's emotions and feelings without taking much stress and anxiety on his own. Moreover, there is a scarcity of technology to support real time socio-emotional interaction for an Autistic. Treatments involving robotics also do not fulfill the role in this case; thus, there is a dire need of a proficient user interface focused particularly on 'systematic' empathy enhancement.

\subsection{Interactive Verbal Behaviour Approach in UIs with Virtual Agents}

The serious game platform named as ECHOE, mentioned in [35] is another attempt made by a group of researchers that used the multi-touch interfacing methodology to design a platform for Autistic Spectrum Disorder patients. The said interface is not necessarily sensitive to collaborative gesture; because, the main scheme of this game is to let the ASD affected child interact in person with a virtual agent named as ANDY. ANDY is basically a cartoon character within the game that interacts with the child and helps him socialize and communicate via eye gaze recognition of the child. This interface is different from the other multi touch interfaces reviewed in this survey, in the context that this interface employs eye gaze recognition to introduce collaboration of the virtual agent (and when needed, the trainer) with the child. During the survey done in [35], a good number of such ASD affected children spoke up who were completely non-communicative before being accustomed to this game. Research in this technology-enhanced environment is still underway and the next generation of the project that is ECHOES-2 is yet to come with new goals and objectives.

The ECHOES project mentioned in [35] has further been advanced to the SHARE-IT project [36]. The acronym SHARE-IT stands for School Home Autism Research Environment through Intelligent Technologies. According to the online website of this project, it is an effort to involve lay-people - other than the therapists or UI designers - like parents and teachers into the treatment of children with ASD. This innovation in the field of ASD management would lead to the child's learning in different places other than the psychologists clinic, prominent of which are the school and home of his. The motivation came from the ECHOES project that showed that there is a need to bridge the gap between an ASD child's development in home and school.

Mehran University Research Journal of Engineering \& Technology, Volume 35, No. 4, October, 2016 [p-ISSN: 0254-7821, e-ISSN: 2413-7219] 
In order to investigate the effectiveness of multi-touch interfaces for enhancement of collaboration among ASD affected children, the comparison presented in the case study done in [37] is worth noticing. According to this study, the Diamond Touch Table proved helpful in designing the 'OurSpace' application that supported both single touch and multi touch operation modes. Moreover, the basic purpose of designing this application was to let the children familiarize with multi-touch surfaces in particular [38]. This was accomplished by bringing in a shared space design task for the targeted children in a class room environment. The activity of organizing desks and seats for children in the virtual class room, with virtual children (icons) resulted in an enhanced reasoning-andcompromise based collaboration among the children. Apart from this, the authors of [38] have also analyzed the individual child's position in the seating arrangement for Diamond Touch Table and the effect of each child's position in the extent of his participation in the activity (Table 1).

In the race of UI development for children with special needs, we notice that $3 \mathrm{D}$ graphics are a contributing factor towards the UIs improvement. Face 3D is one such application developed at the University of Calabria, Italy [39]. Focusing on the IPad-based version for this application, we deduce that the UI that comprises three different GUIs is basically multi-touch based. Contrary to other conventional systems, the collaborative gesture recognition offered in the UI for Face 3D is based not on the collaborative touches of different users, but on the multiple touches of the same user. This ultimately enhances his collaboration with others, in the sense that the application itself is based on emotion learning using the virtual faces of himself, his parents, guardians and peers [40]. Fig. 5 depicts an illustration from this interface. The UI consists of three further GUIs; namely, Face 3D Editor, Face 3D recorder and Virtual Theatre. The standard emotions that the user is able to model in a virtual face are of anger, surprise, joy, sadness, disgust, fear and attention. This innovation turned out to be valuable to aid the HighFunctioning Autistic children familiarize with social sentiments and emotions.

The motivation for employment of virtual agents in UIs for Autism has come from the perceptible hesitation they have while communicating with people, in person or faceto-face. In order to enable richer socializing and communicating skills among Autistic children, some means of direct interaction of the child and trust building was necessary. Virtual agents are an inventive solution to address this problem. This because rather than communicating with people in real life, Autistic children tend to feel more comfortable with technology in isolation. Teaching them communication skills this way, using the UIs centered on such agents enables realistic communication acts such as facial expression of emotions, information structure and emphasis, iconic gestures turntaking in group conversations in trainings [41]. Another plus point with UIs having virtual agents is that the interactions are quite close to human-human interactions [42]. Moreover, autonomous virtual agents like the one employed in the ECHOES project [43] provide grounds for autism intervention. They agents provide one-to-one

TABLE 1. INVESTIGATION INTO CBT - BASED USER INTERFACES FOR AUTISM TREATMENT

\begin{tabular}{|c|l|l|}
\hline User Interface & \multicolumn{1}{|c|}{ Training Focus } & \multicolumn{1}{c|}{ Special Features } \\
\hline Story Table Interface [27] & $\bullet \begin{array}{l}\text { Cooperation enhancement } \\
\text { Smart phone assisted life skill functioning }\end{array}$ & $\begin{array}{l}\bullet \bullet \\
\text { Group activity in the form of story telling } \\
\text { Persuasive technology design }\end{array}$ \\
\hline Join - In suite of serious games [28] & $\bullet \quad$ Social Competence & $\begin{array}{l}\text { Cognitive behavioural therapy } \\
\text { Ecological validity in the UI design }\end{array}$ \\
\hline SCERTS [29] & $\bullet \begin{array}{l}\text { Social communication } \\
\text { Emotional regulation } \\
\text { Transactional support }\end{array}$ & $\begin{array}{l}\text { Cognitive behavioural therapy } \\
\text { Ecological validity in UI design }\end{array}$ \\
\hline
\end{tabular}

Mehran University Research Journal of Engineering \& Technology, Volume 35, No. 4, October, 2016 [p-ISSN: 0254-7821, e-ISSN: 2413-7219] 
correspondence and support that the Autistic child actually needs. The pro-activeness of autonomous agents is necessary for improvement in the Autistic child's motivation and attention seeking abilities.

Literature shows the other side of the picture as well; since there also came situations in trainings where the agents increased users' anxiety and affected their performance just as if they were being watched by a real human [44]. One pitfall of virtual agent based user interfaces is that once the child becomes accustomed to his virtual friend, he tends to become isolated from the other world. This phenomenon can be reduced by focusing on the 'talk' that the virtual agent does with the child; with more emphasis on family importance and socializing with classmates and peers.

\section{RESULTS AND FINDINGS}

Table 2 encapsulates the details of work done in the field of interface designing, in terms of Autism Spectrum Conditions in specific. After close observation and information gathering, the key areas of aid provided by the listed UIs are highlighted. This throws light on the features that are helpful to the trainers, parents and the
ASD affected children themselves. Moreover, the study discussed above has led to another important finding as shown in Fig. 6. It gives an estimate of popularity levels of the different hardware devices that have been used by researchers to support their UIs in settings for different commercial projects.

The commercial projects discussed in Table 2 have been selected from the various behavioral interventions discussed in section 2. During the scrutiny, focus areas were the use of these UIs in Autism treatment, hardware supporting these applications and the number of simultaneous users. These three characteristics respectively indicate quantitative measures of the targeted behavioral intervention, the reliability \& ease and the collaborative platform provided to the users. Together, they give a qualitative estimate of the usefulness of each project's interface.

As far as the five classes of computer-based behavioral interventions are concerned, we have deduced the pros, cons and some future directions for UI designers working in each class. The key findings are as under:
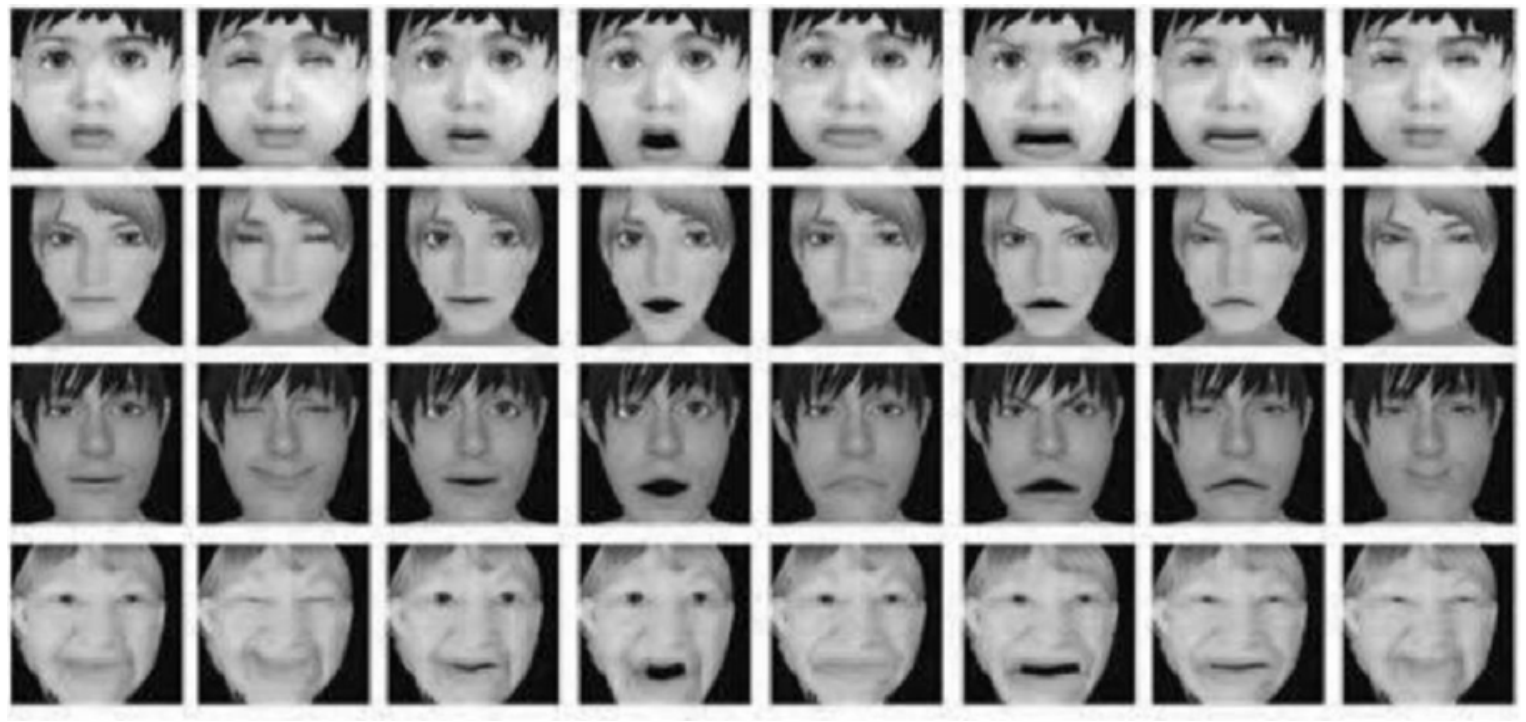

FIG. 5. 3D VIRTUAL AGENTS, IN DIFFERENT EMOTIONS, DEPICTING THE AUTISTIC CHILD, HIS PARENTS AND GRANDPARENTS (IMAGE ADAPTED FROM [43])

Mehran University Research Journal of Engineering \& Technology, Volume 35, No. 4, October, 2016 [p-ISSN: 0254-7821, e-ISSN: 2413-7219] 
(1) Web based interfaces like the Interactive Autism Network and its online portals are more helpful for the parents/ teachers of autistic children than the children themselves. These UIs are sophisticated enough for mature users but they lack in features that attract Autistic children. Hence, they tend to enjoy serious games more than online portals. Autistic adults are more biased towards web-based interfaces.

(2) DTT based UIs are more user-centered than the other four types of UIs studied. This is so because these UIs don't work alone; they rather require the children to involve in a DTT based activity as well. Results from statistical tests done in the various projects show that using these UIs with DTT sessions has made considerable improvement in these sessions.

As compared to DTT-based UIs, CBT-based UIs involve lesser activities. The ultimate meaning of this is that these UIs rely on their own features only. This increases the demand of effective interface designing in these UIs. Authors of the research work discussed in section 2.5 have observed positive changes in their experimental groups. These changes were in terms of problem solving, understanding skills and learning with patience.

(4) Lesser work was found in the domain of empathy enhancement. This is so because the UIs being designed presently have their prime focus on specific impairments. This narrow focus is good in terms of research, but it also indicates that lack of empathy cannot be inter-mixed with other impairments. Explicit work needs to be done for this behavioral impairment.

(5) A wide range of work has been done on UIs with virtual agents to foster verbal behavior approach. As compared to the other four types of UIs, this type is lesser collaborative: it involves a smaller group of children or mostly a single child. This is so because the virtual agent is enough to provide company to the child. Interaction with the reviewed interfaces led to enhanced socializing skills in the experimental group. Moreover, these UIs provide a sense of gesture and emotion recognition in Autistic children.

It is note-worthy here that the study is based on Multitouch collaborative gesture recognition based UIs only. Other methodologies of ASD treatment do exist; for example, the use of Human-Robot Interaction to aid in ASD treatment; however, the current study does not consider these techniques. In order to make the review specific (and HCI-oriented), we have focused on only multi-touch collaborative gesture recognition based UIs. Interventions like tangible UIs and Human-Robot Interactions are unlike our focal point of research, and are wider in their own. It was determined that the literature review be converged to multi-touch based UIs only.

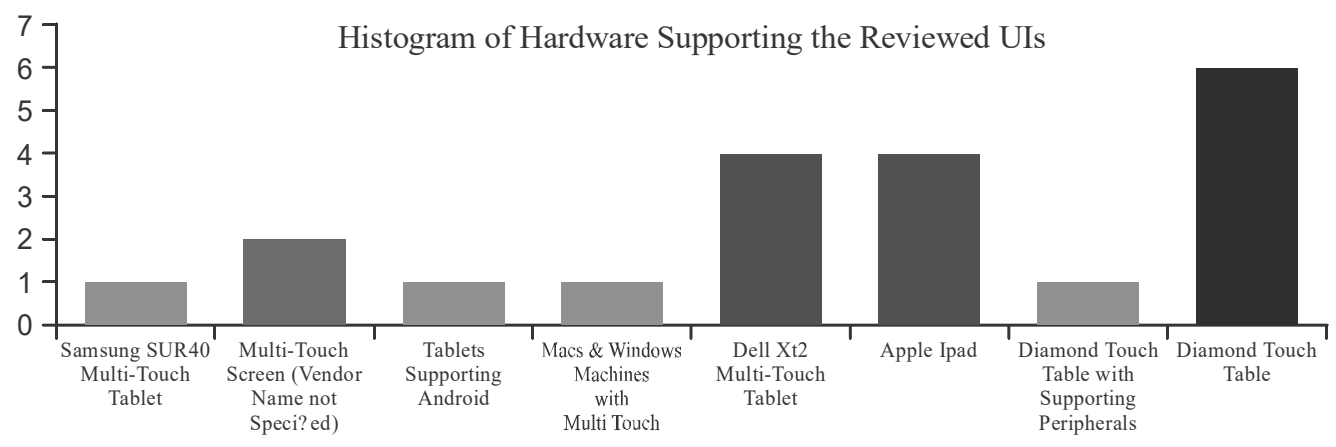

FIG. 6. HISTOGRAM OF HARDWARE SUPPORTING THE REVIEWED UIS 
TABLE 2. SUMMARY OF MULTI-TOUCH UIS DEVELOPED EXPLICITLY TO AID IN THE TREATMENT OF AUTISM SPECTRUM DISORDER CONDITIONS

\begin{tabular}{|c|c|c|c|c|c|c|}
\hline No. & $\begin{array}{l}\text { Multi-touch collaborative } \\
\text { gesture recognition based } \\
\text { UI Projects }\end{array}$ & $\begin{array}{l}\text { Use in the treatment of Autism } \\
\text { Spectrum Disorder }\end{array}$ & Supported hardware & $\begin{array}{c}\text { No. of simultaneous collaborative } \\
\text { users }\end{array}$ & Project URL & $\begin{array}{l}\text { Referen- } \\
\text { ce }\end{array}$ \\
\hline 1. & $\begin{array}{l}\text { Poetry Table using } \\
\text { Diamond Spin tool kit }\end{array}$ & $\begin{array}{c}\text { Enhancement of social collaborative } \\
\text { skills in a group of ASD affected } \\
\text { children }\end{array}$ & $\begin{array}{l}\text { Diamond Touch Table, Ceiling } \\
\text { mounted video projector }\end{array}$ & 4 (including children and the trainer) & http://diamondspin.free.fr/ & [46] \\
\hline 2 & Collaborative Puzzle Game & $\begin{array}{l}\text { Rehabilitation of social abilities in } \\
\text { ASD affected boys. }\end{array}$ & Diamond Touch Table & 4 children & $\begin{array}{c}\text { https://sites.google.com/site/autismte- } \\
\text { chnology/tools-for-Social-Behavior-- } \\
\text { and-Affect/conversation-skills/colla- } \\
\text { borative-learning-puzzle-game }\end{array}$ & [47] \\
\hline 3. & $\begin{array}{l}\text { SIDES (Shared Interfaces } \\
\text { to Develop Effective Social } \\
\text { Skills) }\end{array}$ & $\begin{array}{l}\text { Social skills development in } \\
\text { Asperger's Syndrome patients }\end{array}$ & Diamond Touch Table & $4(11-14$ years old $)$ & $\begin{array}{c}\text { http://ldtprojects.stanford.edu/ emo- } \\
\text { brien/masters_website/index.html }\end{array}$ & [48] \\
\hline 4. & Go Talk Now Application & $\begin{array}{l}\text { Enhancement of Augmentative and } \\
\text { Alternative Communication (AAC) } \\
\text { skills in children having ASD. }\end{array}$ & IPad tablet computer & 3 children (aged 1.5 to 3 years old) & $\begin{array}{c}\text { http://www.attainmentcompany.com/- } \\
\text { gotalk-now } \\
\text { https://itunes.apple.com/us/app/gotal- } \\
\text { k-now/id454176457?mt=8 }\end{array}$ & [49] \\
\hline 5. & I Know & $\begin{array}{c}\text { Quiz application for the development } \\
\text { of language skills and social } \\
\text { collaboration in ASD affected } \\
\text { children }\end{array}$ & IPad Tablet Computer & 2 Users (The child and his parent) & $\begin{array}{c}\text { http://www.iosnoops.com/appinfo/i-- } \\
\text { know-quiz-creation-app-for-ipad/5- } \\
70172763\end{array}$ & {$[23]$} \\
\hline 6. & I Can Tell & $\begin{array}{l}\text { Story Building application for ASD } \\
\text { affected children, which includes } \\
\text { photos from their daily lives and } \\
\text { enables parental control on the } \\
\text { addition of photos. }\end{array}$ & IPad Tablet Computer & 2 Users (The child and his parent) & $\begin{array}{c}\text { http://www.appdecide.com/app/ios/i-- } \\
\text { can-tell/577511010/ }\end{array}$ & {$[23]$} \\
\hline 7. & $\begin{array}{l}\text { ECHOES Serious Game } \\
\text { based Interface }\end{array}$ & $\begin{array}{l}\text { Communication Skills Development } \\
\text { in Autistic Spectrum Conditions } \\
\text { (ASC) diagnosed children }\end{array}$ & $\begin{array}{l}42 \text { inch Multi-touch LCD Display } \\
\text { (vendor name not specified) }\end{array}$ & $\begin{array}{c}2 \text { (The child ( } 5 \text { to } 7 \text { year old), and } \\
\text { the trainer if required) }\end{array}$ & http://echoproject.ca/ & {$[35]$} \\
\hline 8. & Story Table Interface & $\begin{array}{c}\text { Initiation of positive social interaction } \\
\text { with peers and fellows }\end{array}$ & $\begin{array}{l}\text { MERL's Diamond Touch Table and } \\
\text { Receiving Surface Pad }\end{array}$ & $\begin{array}{c}6(8-11 \text { years })-2 \text { to } 4 \text { at one time } \\
\text { on DT table }\end{array}$ & http $/ /$ hands-project.eu/ & {$[27]$} \\
\hline 9. & Drawing & $\begin{array}{l}\text { Storytelling and creativity building } \\
\text { with free hand drawing having } \\
\text { zooming \& pinching features }\end{array}$ & $\begin{array}{c}\text { Dell XT2 Multi touch tablet (12.1" } \\
\text { screen capable to detect up to } 4 \\
\text { simultaneous touches) }\end{array}$ & 2 to 6 children & $\begin{array}{l}\text { http } / / \text { homepage.cs.uiowa.edu/ hour- } \\
\text { cade/projects/asd/drawing.html }\end{array}$ & {$[50]$} \\
\hline 10. & Untangle & $\begin{array}{l}\text { Puzzle solving in collaboration with } \\
\text { peers }\end{array}$ & Dell XT2 Multi touch tablet & $\begin{array}{l}5 \text { children simultaneously solving the } \\
\text { puzzle }\end{array}$ & $\begin{array}{l}\text { http } / / \text { homepage.cs.uiowa.edu/ hour- } \\
\text { cade/projects/asd/untangle.html }\end{array}$ & {$[50]$} \\
\hline 11. & Photogoo & Emotion recognition in ASD children & Dell XT2 Multi touch tablet & $\begin{array}{l}1 \text { child in } 1 \text { st step, } 3 \text { to } 4 \text { children's } \\
\text { group in the final step }\end{array}$ & $\begin{array}{l}\text { http } / / \text { homepage.cs.uiowa.edu/ hour- } \\
\text { cade/projects/asd/emotion.html }\end{array}$ & {$[50]$} \\
\hline 12. & Music Authoring & Collaborative music composition & Dell XT2 Multi touch tablet & $\begin{array}{l}\text { Multiple children touches OR a } \\
\text { group of 2: the child and an adult } \\
\text { training him on the app }\end{array}$ & $\begin{array}{l}\text { http }: / \text { homepage.cs.uiowa.edu/ hour- } \\
\text { cade/projects/asd } / \text { music.html }\end{array}$ & {$[50]$} \\
\hline 13. & Game Suite Design & $\begin{array}{l}\text { Tangible UI for intuitive social } \\
\text { interaction }\end{array}$ & $\begin{array}{l}\text { Samsung SUR40 Multitouch Table } \\
\text { with Microsoft Pixel Sense }\end{array}$ & $\begin{array}{l}\text { Both single player and multi player } \\
\text { games supported }\end{array}$ & $\begin{array}{l}\text { Project URL not available. } \\
\text { URL of the author's } \\
\text { website: } \\
\text { http://home.hio.no/ weiche/ }\end{array}$ & {$[51]$} \\
\hline 14. & Join-in Suite & $\begin{array}{l}\text { To enhance social competence in } \\
\text { children with high function ASD. }\end{array}$ & Diamond Touch Table & 3 ( 2 children and 1 trainer) & http:/cospatial.fbk.eu/ & {$[28]$} \\
\hline 15. & NoProblem! & $\begin{array}{l}\text { To teach conversational responses } \\
\text { and social skills }\end{array}$ & Diamond Touch Table & 2 to 3 users & http://cospatial.fbk.eu/ & {$[52]$} \\
\hline 16. & Proyect@Emociones & $\begin{array}{c}\text { Android application UI for empathy } \\
\text { enhancement in ASD children in } \\
\text { Chile }\end{array}$ & $\begin{array}{c}\text { Any Android tablet supporting multi- } \\
\text { touch }\end{array}$ & $\begin{array}{l}3 \text { children (aged 8-11 years) Under } \\
\text { supervision of educator/ therapist }\end{array}$ & $\begin{array}{l}\text { https } / / \text { play.google.com/store/apps/d- } \\
\text { etails?id=air.Proyectoemociones\&fe- } \\
\text { ature=search_result\#?t=W251bGw- } \\
\text { sMSwxLDEsImFpci5Qcm95ZWN- } \\
\text { 0b2Vtb2Npb25lcyJd }\end{array}$ & [33] \\
\hline 17. & SHARE-IT & $\begin{array}{c}\text { Advancement of the project } \\
\text { ECHOES [13] - to gap the bridge } \\
\text { between ASD child's development in } \\
\text { school and home }\end{array}$ & $\begin{array}{l}\text { Unity-3D game engine toolkit. } \\
\text { Launched on Windows Machines \& } \\
\text { Macs in July,2013 }\end{array}$ & Under design process & http://shareitproject.org/ & {$[37]$} \\
\hline 18. & $\begin{array}{l}\text { OurSpace: Tabletop } \\
\text { classroom design } \\
\text { application }\end{array}$ & $\begin{array}{l}\text { Multi-touch interface developed for } \\
\text { representing spaces like class rooms } \\
\text { and friendship groups for enhanced } \\
\text { collaboration among ASD children. }\end{array}$ & $\begin{array}{l}\text { Diamond Touch Table with both } \\
\text { single and multi touch support }\end{array}$ & Group of 3 people & http://shareitproject.org/ & {$[38]$} \\
\hline 19. & $\begin{array}{l}\text { Face 3D IPad-based } \\
\text { Version }\end{array}$ & $\begin{array}{c}\text { A multi-touch application to enhance } \\
\text { emotion learning of High functioning } \\
\text { Autistic children, using 3D Facial } \\
\text { Graphics. }\end{array}$ & IPad Tablet Computer & $\begin{array}{l}2 \text { Users (Mainly the child, and the } \\
\text { trainer when required) }\end{array}$ & $\begin{array}{c}\text { http:/www.culturefund.eu/projects/s- } \\
\text { cienar-scientific-scenarios-and-art }\end{array}$ & [39] \\
\hline 20. & Racketeer & $\begin{array}{c}\text { Serious game consisting of six levels } \\
\text { to aid in collaboration and } \\
\text { intelligence-development in ASD } \\
\text { affected children. }\end{array}$ & $\begin{array}{l}\text { Multi-touch screen (vendor name } \\
\text { not specified) }\end{array}$ & 2 children (aged 8 to 12 years) & Project URL not found & {$[45]$} \\
\hline
\end{tabular}

Mehran University Research Journal of Engineering \& Technology, Volume 35, No. 4, October, 2016 [p-ISSN: 0254-7821, e-ISSN: 2413-7219] 


\section{CONCLUSION}

For decades, technology usage has been an effective tool in the treatment of mental disorders; Autism Spectrum Disorder is one of which. This paper has put in a nutshell, the most recent innovations in terms of UI development for kids with Autism as a result of which they hang back from being social and communicative. Research in this regard has therefore been carefully scrutinized, particularly focusing on UIs with multi-touch support that is able to provide collaborative activities for the concerned children. After the comparative review, we conclude that research specifically in multi-touch collaborative gesture recognition based UIs, though not fully in the prime, has highlighted marked potential for treatment of ASD affected children. A lot of room is still there for further work in interface designing in this context; some of which has been briefed in section 3 of the paper. The types of user interfaces for behavioral interventions, along with their respective pros and cons have been described. This provides functional points to be noted for the UI designers before starting on the voyage of UI designing for the treatment of behavioral impairments in ASD affected children.

\section{FUTURE WORK}

Active research in this domain (during the span of 20112015 ) includes a variety of dimensions in UI development. One of these is of adaptive user-centered interfaces. These involve user-centered design methodology. They are adaptive because they integrate characteristics of an Autistic user and then develop an effective user model. Thus, the special needs of such users are better addressed. Furthermore, multi-touch user interfaces are taking directions to bring Autism treatment home with the advent of home-based behavioral interventions via smart phone based UIs. As far as simplicity in UI development is concerned, work is being done on natural user interfaces for pre-schoolers that lack motor skills. This school-of-thought of researchers focuses on two aspects: to start Autism treatment as early as possible and to keep the UI simpler for young Autistics, to better understand the targeted skills.

Apart from multi touch tablet and smart-phone applications, another widely accepted innovation is that of robot assisted therapies and tangible user interfaces. Moreover, UI designers are now focusing on a more HCI oriented work so that they may concentrate on even the slighter deficiencies in attitudes of Autistic children.

\section{ACKNOWLEDGEMENT}

Authors acknowledge the support provided by Department of Computer Software Engineering, University of Engineering \& Technology, Peshawar, Pakistan. This cooperation was in terms of the access to a variety of excellent quality impact factor journals and conference publications.

\section{REFERENCES}

[1] Rapin, I., and Tuchman, R.F., "Autism: Definition, Neurobiology, Screening, Diagnosis”, Pediatric Clinics of North America, Volume 55, No. 5, pp. 1129-1146, 2008 .

[2] Brault, M.W., “Americans with Disabilities: 2010”, US Department of Commerce, Economics and Statistics Administration, US Census Bureau, pp. 70-131, 2010.

[3] Anjum, S., and Ajmal, M., "Evaluation of a Multi-Pronged Intervention with an Autistic Child: A Grounded Action Research", Pakistan Journal of Social and Clinical Psychology, Volume 9, No. 3, 2012. 
[4] Kientz, J.A., Goodwin, M.S., Hayes, G.R., and Abowd, G.D., "Interactive Technologies for Autism", Synthesis Lectures on Assistive, Rehabilitative, and HealthPreserving Technologies, Volume 2, No. 2, pp. 1-177, 2013.

[5] Read, J.C., Hourcade, J.P., Markopoulos, P., and Iversen, O.S., "Child Computer Interaction SIG: Towards Sustainable Thinking and Being”, Proceedings of Extended Abstracts of 32nd Annual ACM Conference on Human Factors in Computing Systems, pp. 11351138. ACM, Toronto, Canada, April, 2014.

Wu, K.C., Tang, Y.M., and Tsai, C.Y, "Graphical Interface Design for Children Seeking Information in a Digital Library", Visualization in Engineering, Volume 2, No. 1, pp. 1-14, 2014.

Korte, J., Potter, L.E., and Nielsen, S., "Great Expectations: What do Children Expect from their Technology?", Proceedings of 52nd ACM Conference on Computers and People Research, pp. 105-111, Singapore, May, 2014.

[8] Chen, W., "Multitouch Tabletop Technology for People with Autism Spectrum Disorder: A Review of the Literature", Procedia Computer Science, Volume 14, pp. 198-207, 2012.

[9]

Holt, S., and Yuill, N., "Facilitating Other-Awareness in Low-Functioning Children with Autism and TypicallyDeveloping Preschoolers Using Dual-Control Technology", Journal of autism and Developmental Disorders, Volume 44, No. 1, pp. 236-248, 2014.

[10] Schuller, B., Marchi, E., Baron-Cohen, S., O'Rielly, H., Robinson, P., Davies I., and Golan, O., "ASC-Inclusion: Integrated Internet-Based Environment for Social Inclusion of Children with Autism Spectrum Conditions", IDGEI 1st International Workshop, Chania, Crete, Greece, 2013.

[11] Daniels, A.M., Rosenberg, R.E., Anderson, C., Law, J.K., Marvin, A.R., and Law, P.A., "Verification of ParentReport of Child Autism Spectrum Disorder Diagnosis to a Web-Based Autism Registry", Journal of Autism and Developmental Disorders, Volume 42, No. 2, pp. 257$265,2012$.
[12] Jordan, C.J., "Evolution of Autism Support and Understanding via the World Wide Web", Intellectual and Developmental Disabilities, Volume 48, No. 3, pp. 220-227, 2010.

[13] Biklen, D., "Representing Autism: Culture, Narrative, Fascination (Review)", Journal of Literary \& Cultural Disability Studies, Volume 1, No. 1, pp. 107-109, 2009.

[14] Doja, A., and Roberts, W., "Immunizations and Autism: A Review of the Literature", The Canadian Journal of Neurological Sciences, Volume 33, No. 4, pp. 341-346, 2006.

[15] Melling, R., "Worlds of Autism: Across the Spectrum of Neurological Difference", Educational Psychology in Practice, Volume 30, No. 2, pp. 208-209, 2014.

[16] Fleischmann, A., "The Hero's Story and Autism Grounded Theory Study of Websites for Parents of Children with Autism", Autism, Volume 9, No. 3, pp. 299-316, 2005.

[17] Green, V.A., Pituch, K.A., Itchon, J., Choi, A., O'Reilly, M., and Sigafoos, J., "Internet Survey of Treatments used by Parents of Children with Autism”, Research in Developmental Disabilities, Volume 27, No. 1, pp. 7084, 2010.

[18] Center, V.E., "Vaccines and Autism: What You Should Know", Vaccine Education Centre at the Children's Hospital of Philadelphia, Volume 1, Summer, 2008.

[19] Wakefield, A.J., Murch, S.H., Anthony, A., Linnell, J., Casson, D.M., Malik, M., Berelowitz, M., and WalkerSmith, J.A., "RETRACTED: Ileal-Lymphoid-Nodular Hyperplasia, Non-specific Colitis, and Pervasive Developmental Disorder in Children", The Lancet, Volume 351, No. 9103, pp. 637-641, 1998.

[20] Mitchell, C., “Autism e-Mailing Lists”, He@11th Information on the Internet, Volume 33, No. 1, pp. 3-4, 2003. 
[21] Alessandrini, A., Cappelletti, A., and Zancanaro, M., "Audio-Augmented Paper for the Therapy of LowFunctioning Autism Children", ACM Extended Abstracts on Human Factors in Computing Systems, pp. 505-510, Paris, April, 2013.

[22] Picardo, V., Metson, S., Hoda, R., Amor, R., ArnoldSaritepe, A., Sharp, R., and Brand, D., "Designing an Educational Tabletop Software for Children with Autism”, Proceedings of $15^{\text {th }}$ Australasian User Interface Conference, Volume 150, pp. 89-90, Australian Computer Society, Inc., January, 2014.

[23] Wadhwa, B., and Jianxiong, C.C., "Collaborative Tablet Applications to Enhance Language Skills of Children with Autism Spectrum Disorder", Proceedings of $11^{\text {th }}$ Asia Pacific Conference on Computer Human Interaction, pp. 39-44, Bangalore, India, 2013.

[24] Sundberg, M., and Partington, J., "The Need for Both Discrete Trial and Natural Environment Language Training for Children with Autism", Autism: Behavior Analytic Perspectives, pp. 139-156, 1999.

[25] Steege, M.W., Mace, F.C., Perry, L., and Longenecker, H., “Applied Behavior Analysis: Beyond Discrete Trial Teaching", Psychology in the Schools, Volume 44, No. 1, pp. 91-99, 2007.

[26] Ms, M., and Amy, K., “Applied Behavior Analysis Techniques: Discrete Trial Training \& Natural Environment Training”, Southern Illinois University Carbondale Open SIUC, December, 2011.

[27] Mintz. J., "The Role of User Emotional Attachment in Driving the Engagement of Children with Autism Spectrum Disorders (ASD) in Using a Smartphone App Designed to Develop Social and Life Skill Functioning", Computers Helping People with Special Needs, pp. 486493, Springer, 2014.
[28] Zancanaro, M., Giusti, L., Gal, E., and Weiss, P.T., "Three Around a Table: The Facilitator Role in a Co-Located Interface for Social Competence Training of Children with Autism Spectrum Disorder", Human-Computer Interaction-INTERACT, pp. 123-140, Springer, Berlin Heidelberg, 2011.

[29] Prizant, B.M., Wetherby, A.M., Rubin, E., and Laurent, A.C., "The SCERTS Model: A Transactional, Family Centered Approach to Enhancing Communication and Socioemotional Abilities of Children with Autism Spectrum Disorder", Infants \& Young Children, Volume 16, No. 4, pp. 296-316, 2003.

[30] Ames, M., and Weiss, J., "Cognitive-Behaviour Therapy for a Child with Autism Spectrum Disorder and Verbal Impairment: A Case Study", Journal on Developmental Disabilities, Volume 19, No. 1, pp. 61-69, 2013.

[31] Reaven, J.A., Blakeley-Smith, A., Nichols, S., Dasari, M., Flanigan, E., and Hepburn, S., “Cognitive-Behavioral Group Treatment for Anxiety Symptoms in Children with High-functioning Autism Spectrum Disorders a Pilot Study", Focus on Autism and Other Developmental Disabilities, Volume 24, No. 1, pp. 27-37, 2009.

[32] Kiep, M., Spek, A.A., and Hoeben, L., "MindfulnessBased Therapy in Adults with an Autism Spectrum Disorder: Do Treatment Effects Last?”, Mindfulness, Volume 6, No. 3, pp. 637-644, 2014.

[33] Munoz, R., Barcelos, T., Noel, R., and Kreisel, S., "Development of Software that Supports the Improvement of the Empathy in Children with Autism Spectrum Disorder”, IEEE 31st International Conference on Chilean Computer Science Society, pp. 223-228, Valparaiso, Chile, November, 2012.

[34] elKaliouby, R., Picard, R., and Baron Cohen, S.I.M.O.N., "Affective Computing and Autism", Annals of the New York Academy of Sciences, Volume 1093, No. 1, pp. 228-248, 2006. 
[35] Bernardini, S., Porayska-Pomsta, K., and Smith, T.J., "ECHOES: An Intelligent Serious Game for Fostering Social Communication in Children with Autism", Information Sciences, Volume 264, pp. 41-60, 2014.

[36] Porayska-Pomsta, K., Anderson, K., Bernardini, S., Guldberg, K., Smith, T., Kossivaki, L., Hodgins, S., and Lowe, I., "Building an Intelligent, Authorable Serious Game for Autistic Children and Their Carers", Advances in Computer Entertainment, pp. 456-475, Springer International Publishing, Switzerland, 2013.

[37] Yuill, N., and Rogers, Y., "Mechanisms for Collaboration: A Design and Evaluation Framework for Multi-User Interfaces", ACM Transactions on Computer-Human Interaction, Volume 19, No. 1, pp. 1, 2012.

[38] Rick, J., Harris, A., Marshall, P., Fleck, R., Yuill, N., and Rogers, Y., "Children Designing Together on a MultiTouch Tabletop: An Analysis of Spatial Orientation and User Interactions", Proceedings of 8th International Conference on Interaction Design and Children, pp. 106114. ACM, Como, Italy, June, 2009.

[39] Bertacchini, F., Bilotta, E., Gabriele, L., Olmedo Vizueta, D.E., Pantano, P., Rosa, F., Tavernise, A., Vena, S., and Valenti, A., "An Emotional Learning Environment for Subjects with Autism Spectrum Disorder", IEEE International Conference on Interactive Collaborative Learning, pp. 653-659, Kazan, Tatars tan, 2013.

[40] Adamo, A., Bertacchini, P.A., Bilotta, E., Pantano, P., and Tavernise, A., "Connecting Art and Science for Education: Learning through an Advanced Virtual Theater with "Talking Heads", Leonardo, Volume 43, No. 5, pp. 442-448, 2010.

[41] Marsi, E., and van Rooden, F., "Expressing Uncertainty with a Talking Head in a Multimodal QuestionAnswering System”, MOG Workshop on Multimodal Output Generation, Enschede, the Netherlands, January, 2007.
[42] Hernández, Á., López, B., Díaz, D., Fernández, R., Hernández, L., and Caminero, J., "A Person in the Interface: Effects on User Perceptions of Multibiometrics", Proceedings of Workshop on Embodied Language Processing, pp. 33-40, Association for Computational Linguistics, Prague, Czech Republic, June, 2007.

[43] Bernardini, S., Porayska-Pomsta, K., Smith, T.J., and Avramides, K., "Building Autonomous Social Partners for Autistic Children”, Intelligent Virtual Agents, pp. 46-52. Springer Berlin Heidelberg, January, 2012.

[44] Rickenberg, R., and Reeves, B., "The Effects of Animated Characters on Anxiety, Task Performance, and Evaluations of User Interfaces", Proceedings of SIGCHI Conference on Human Factors in Computing Systems, ACM, the Hague, the Netherlands, April, 2000.

[45] Van Veen, M.,A., de Vries, F., Cnossen, and Willems, R., "Improving Collaboration for Children with PDD-NOS through a Serious Game with Multi-Touch Interaction", Proceedings of EDULEARN, pp. 3559-3570, Barcelona, Spain, 2009.

[46] Shen, C., Vernier, F. D., Forlines, C., \& Ringel, M., "DiamondSpin: An Extensible Toolkit for Around-thetable Interaction," In Proceedings of the SIGCHI conference on Human factors in computing systems, pp. 167-174. ACM, Vienna, Austria, April 2004.

[47] Battocchi, A., Pianesi, F., Tomasini, D., Zancanaro, M., Esposito, G., Venuti, P., Sasson, A.B., Gal, E., and Weiss, P.L., "Collaborative Puzzle Game: A Tabletop Interactive Game for Fostering Collaboration in Children with Autism Spectrum Disorders," Proceedings of ACM International Conference on Interactive Tabletops and Surfaces, pp. 197-204, ACM, Banff, Canada, 2009.

[48] Piper, A.M., O’Brien, E., Morris, M.R., and Winograd, T., "SIDES: A Cooperative Tabletop Computer Game for Social Skills Development", Proceedings of 20th Anniversary Conference on Computer Supported cooperative Work, pp. 1-10. ACM, Banff, Canada, January, 2006. 
[49] Gevarter, C., O’Reilly, M.F., Rojeski, L., Sammarco, N., Sigafoos, J., Lancioni, G.E., and Lang, R., "Comparing Acquisition of AAC-Based Minds in Three Young Children with Autism Spectrum Disorder Using iPad® Applications with Different Display and Design Elements", Journal of Autism and Developmental Disorders, Volume 44, No. 10, pp. 2464-2474, 2014.

[50] Hourcade, J.P., Bullock-Rest, N.E., and Hansen, T.E., "Multitouch Tablet Applications and Activities to Enhance the Social Skills of Children with Autism Spectrum Disorders", Personal and Ubiquitous Computing, Volume 16, No. 2, pp. 157-168, 2012.
[51] Chen, W., "Designing Tangible and Multitouch Games for Autistic Children", Computers Helping People with Special Needs, [ISBN: 9783319085968], pp. 502-505, Springer, Switzerland, 2014.

[52] Zancanaro, M., Giusti, L., Bauminger-Zviely, N., Eden, S., Gal, E., and Weiss, P.L., "No Problem! A Collaborative Interface for Teaching Conversation Skills to Children with High Functioning Autism Spectrum Disorder", Playful User Interfaces, pp. 209-224, Springer, Singapore, 2014.

Mehran University Research Journal of Engineering \& Technology, Volume 35, No. 4, October, 2016 [p-ISSN: 0254-7821, e-ISSN: 2413-7219] 560 